International Journal of Social Sciences and Humanities
Available online at http://sciencescholar.us/journal/index.php/ijssh
Vol. 3 No. 2, August 2019, pages: 261 276
e-ISSN: 2550-7001, p-ISSN: 2550-701X
https://doi.org/10.29332/ijssh.v3n2.327

\title{
Errors of Entrepreneur in Nigeria: The Blue Ocean Strategy as
} Panacea

\author{
CrossMark \\ Kifordu A. Anthony a, F. Igweh ${ }^{\text {b }}$, Agbor Stephen ${ }^{c}$ \\ Article history: Received 18 December 2018, Accepted: 30 April 2019, Published: 29 August 2019
}

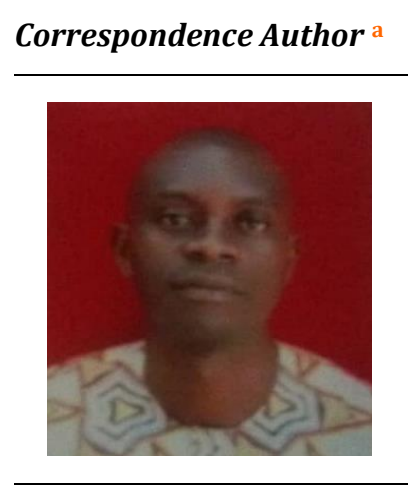

Keywords

blue ocean strategy; entrepreneurs; syndrome red ocean; small scale; value innovations;

\begin{abstract}
Nigeria's harsh economy has posed business planning challenges to many small and medium scale entrepreneurs. In a bid to thrive, some of these business entrepreneurs often commit errors along the path of entrepreneurship. While most errors are helpful to the business, others are harmful. The blue ocean strategy (BOS) is an up-to-the-minute approach of thoughts; a bold, recent path to winning the future. This study conceptualizes with empirical data the common errors of a number of the entrepreneur in Nigeria and highlights the BOS as a panacea. The paper identified two objectives; to determine the effect of planning error on entrepreneurs' success in Nigeria and the effect of Blue Ocean Strategy on the Success of Entrepreneurs in Nigeria. Statistically, two research questions and hypotheses were formulated. The descriptive statistics of simple frequency count and simple percentage were used for description and analysis. To test the hypotheses formulated, chi-square method is employed. This method is used because it is good in testing the validity of the hypothetical statement especially to study the relationship between two or more variables and finding revealed that Small Scale Enterprises plays important role in supplying the needs of large industries. It was recommended that those entrepreneurs who stuck in the red oceans should employ the Blue Ocean Strategy's analytical tools and frameworks. Someone definitely created every business and market space while it was new. It can certainly be you.
\end{abstract}

e-ISSN: 2550-7001, p-ISSN: 2550-701X ๑ Copyright 2019. The Author. SS Journals Published by Universidad Técnica de Manabí. This is an open-access article under the CC BY-SA 4.0 license

(https://creativecommons.org/licenses/by-sa/4.0/) All rights reserved.

\footnotetext{
a Edo University Iyamho, Edo State, Nigeria

b Delta State Polytechnic Ogwashi-Uku, Nigeria

c Delta State Polytechnic Ogwashi-Uku, Nigeria
} 


\section{Contents}

Abstract

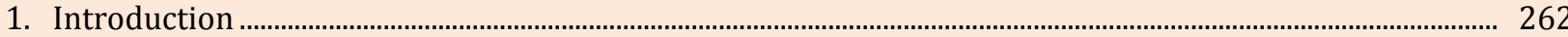

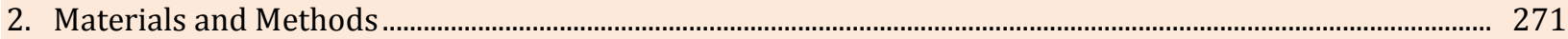

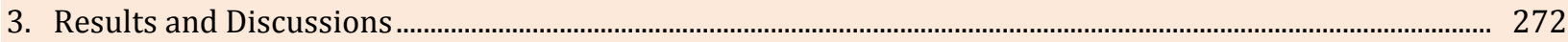

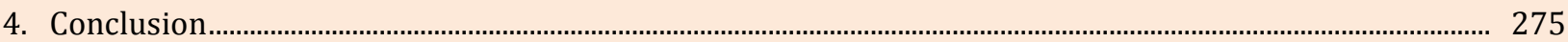

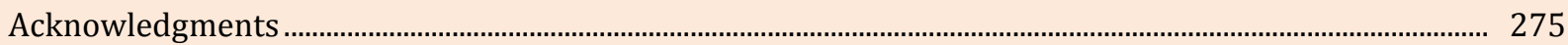

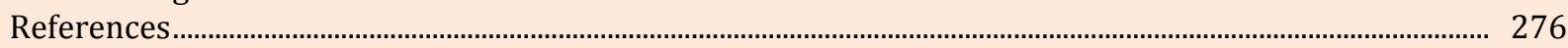

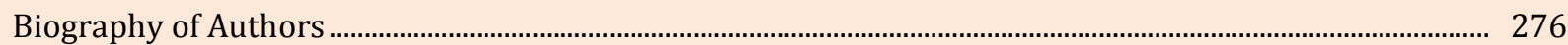

\section{Introduction}

Nigeria's harsh economy has posed business planning challenges to many small and medium scale entrepreneurs. In a bid to thrive, some of these business entrepreneurs often commit errors along the path of entrepreneurship. These mistakes help you learn how to do things better the next time you are faced with a challenge and give you the motivation to continually move your business forward. While most mistakes that you make as an entrepreneur will teach you a thing or two about the way to run your business, others can be detrimental or at the very least costly to your long-term plans. As many as $25 \%$ of new businesses in their first year will fail, according to National Bureau for Statistics (2015), and these numbers become even grimmer by the end of the first five years of business ownership. To avoid becoming a statistic, it is imperative that you avoid some of the bigger entrepreneurial errors, so that your good idea isn't pulled under by a bad call. Know your industry. This doesn't mean you must have done market research: That isn't enough. You need to actually work in that industry, and learn from those who have been there. Assuming you know enough from reading a book is a huge mistake. If you have an idea you like, great, get a job in that field working for someone else, learn what it actually takes to be there, as well as what works and what doesn't. Then open your shop.

Also, there is a mistake of trying to launch a new startup before the current one had time to mature. Entrepreneurs lose a lot of resources. However, mistakes need to be made in order to become a better entrepreneur. These mistakes strengthen the experience and culture of a successful entrepreneur. It was a hard time, but it's the mistakes that will help entrepreneurs grow and become successful. Hiring has always been another weakness. On the assumption that I want to believe that because I am a good person, I will always attract good people. I realized that hiring requires a different type of talent, one that is tailored more toward using discernment to discover if a person would be a good fit. Over time, I noticed that it's more about chemistry than skills that work in a people-centered team environment. This is the classic "chicken and egg" problem of which comes first. I assure you that most investors will not take you seriously if you don't have a real company, so you may wait forever (Kim, 2005; Kim et al., 2005; Mauborgne, 2004).

In the heat of scaling the business, it's tempting to skip the cost and time of finding qualified job candidates and enlist those close at hand, without paying them a competitive wage for the hard work and commitment you need. Very few people are experts in all facets of a new business, including finance, sales, marketing, and operations. The best strategy is to hire people who are smarter than you (in their domain) and allow you to learn from them, rather than the other way around. Moderate business conflict is constructive and should be embraced. New business owners should be signing every payment, and managing every expense. The accountant may accurately record every transaction, but only you can make the strategic trade-offs on marketing costs versus customer revenue, product quality versus support, and so forth.

\section{Statement of the problem}

Too many business owners in Nigeria are convinced that listening to an advisory board or Board of Directors or consulting is a waste of time and money. As a result, they repeat the mistakes of peers and also tend to repeat their own mistakes. Advisors and mentors enhance the learning and effectiveness of even the best business leaders. I'm sure that experienced business owners can add one or two more key items to their assessment list. The reality is that making mistakes is a necessary part of every successful business growth effort, as long as you avoid the mistakes of others, and don't keep making the same mistakes over and over 
again. The other extreme shortcut of Nigerian Entrepreneurs is never trying anything new, which is always a mistake in business. You can't win if you don't try to push the limits. Work hard, but work smart. The objectives of the present paper are to determine the effect of planning error on entrepreneurs success in Nigeria and effect of blue ocean strategy on the success of entrepreneurs in Nigeria. The research objectives are included (1) Do Planning Error affect Entrepreneurs Success in Nigeria? And (2)Does Blue Ocean strategy promote success of Entrepreneurs in Nigeria?

\section{Hypotheses}

Ho1: $\quad$ The Planning Errors do not reduce Entrepreneurs success in Nigeria

$\mathrm{H}_{1}$ : The Planning Errors reduce Entrepreneurs success in Nigeria

Ho2: $\quad$ Blue Ocean strategy do not promote the success of Entrepreneurs in Nigeria?

$\mathrm{H}_{2}$ : Blue Ocean strategy promotes success of Entrepreneurs in Nigeria?

\section{Literature Review \\ Conceptual clarification}

In order to critically explore this study, certain concepts will need to be critically examined. Those concepts are blue ocean strategy, entrepreneurship in Nigeria, and planning errors. Blue Ocean is an analogy to describe the wider, deeper potential of market space that is not yet explored (Kim \& Mauborgne, 2005). Although the term may be new, blue oceans have always been with us (Kim \& Mauborgne, 2005). Blue Ocean Strategy is a method of creating a business strategy of the enterprise, which was described in a book by W. Chan Kim and Renee Mauborgne. Blue Ocean Strategy is based on the idea that every enterprise can achieve higher profit by creating new demand in non-competitive market (so-called Blue Ocean). The Blue ocean strategy was designed to create new focus and approach to combating bureaucratic inefficiency. Kim \& Mauborgne (2004) identified; creating an uncontested market, making of competition irrelevant, creating and capturing of new demands, break the value/cost trade-off and aligning the whole system of a company's activities in pursuit of differentiation and low costs which is the basic principles that guide the adoption of the blue ocean strategy. The dominant role played by the government in some national activities needs to be abandoned and the available public fund diverted elsewhere to areas of little patronage.

The strategy here is the process of competing to be unique rather than competing to be the best, although a military background has been traced to the term it has been adopted more widely in organizational management. It involves defining a unique value proposition through which the organization will achieve and maintain competitive advantage. It involves developing a different and tailored "value chain" or set of activities that support and help to differentiate the organization's strategy. It involves deciding what not to do as much as what to do. The Longman Dictionary of Contemporary English, Third Edition sees strategy as "a well-planned series of actions for achieving an aim, especially success against an opponent or threat". In order to critically explore the concept of blue ocean strategy, the term "Red oceans" will as well be examined. The metaphor of red and blue oceans describes the market universe. Red oceans are all the industries in existence today-the known market space. In the red oceans, industry boundaries are defined and accepted, and the competitive rules of the game are known. Here companies try to outperform their rivals to grab a greater share of the product or service demand. As the market space gets crowded, prospects for profits and growth are reduced. Products become commodities or niche, and cutthroat competition turns the ocean bloody. Hence, the term red oceans. Blue oceans, in contrast, denote all the industries not in existence today-the unknown market space, untainted by competition. In blue oceans, demand is created rather than fought over. There is ample opportunity for growth that is both profitable and rapid. In blue oceans, competition is irrelevant because the rules of the game are waiting to be set (Ogundiya, 2011; Oosterbroek, 2007).

\section{Entrepreneurship in Nigeria}

Entrepreneurship is the process of establishing a new firm, taking the risk and making profit in the process. Entrepreneurship or business enterprises refers to it as a group of skills, which includes the ability to combine land, labour and capitals in the most efficient way, the willingness to run the risk of the business

Anthony, K. A., Igweh, F., \& Stephen, A. (2019). Errors of entrepreneur in Nigeria: the blue ocean strategy as panacea. International Journal of Social Sciences and Humanities, 3(2), 261-276. 
failure and the creativity required to invent new products and new ways to market them. Entrepreneurship can be considered a special type of human resources. Entrepreneurship is the act or process of getting into and managing your own business enterprises. This involves any form of innovation that has a bearing on the welfare of the firm.Entrepreneurial forces are relatively strong in this country, as the lack of jobs and a rise in poverty leave few other options for the Nigerian people. Although difficult due to a lack of resources, there are non-profit organizations such as the Fate Foundation in Nigeria that are dedicated to promoting entrepreneurship (Bolarinwa, 2005; Kim et al., 2008).

Apart from the information about Nigeria that is so widespread and often negative, there appears to be a recognition of the critical role and place of technology in the development and advancement of the nation. In the past few years, there have been the start-ups of internet cafes, new Internet Service Providers, computers in some schools, and connectivity hubs that provide access to information at high speeds. The Nigerian government has created and adopted policies promoting the use of technology in education. The Nigerian Economic Policy 1999-2003, is a comprehensive compendium of President Obasanjo's policies and guiding principles for the nation. The policy states: "Government will provide affordable quality education for all Nigerians, the Universal Basic Education, and mass Adult Literacy programs will be pursued in earnest" and in particular, "Government will create incentives to expand access to information and communications technology which will facilitate leap-frogging in order to short-circuit the longer span of development." The policy even recommends partnerships with national and international agencies including the United Nations Transfer of Knowledge through Expatriate Nationals program or TOKTEN as it is commonly known.

However, an important distinction between developed and developing nations often lies in the wide disparity between policy pronouncements and policy implementation. Often, signs of this disparity are found in the extent that policies are clear and measurable and that application is consistent. Often developing nations adopt excellent policies and guidelines that could, if well implemented, change the futures of their citizens but alas, they are very often not followed through. If Nigeria follows-through with its new laws guiding education and technology with action and implementation, and the people of Nigeria attain their educational goals and professional potential with the tools available to the world today we will witness the transformation of what is presently a Third world giant (or toothless bulldog) into an Emerging economic giant (Ajadi, 2010).

\section{The Nature of Entrepreneurship in Nigeria}

Entrepreneurship activity in Nigeria is primarily based on the necessity with majority of entrepreneurs in the country operating in Lagos, the former capital of the country and Nigeria's economic decline since the 1980s has created a hostile environment that is unfavorable to entrepreneurial success. The Nigerian infrastructure limits entrepreneurial effectiveness and is a barrier to success and the high cost of doing business in Nigeria, such as the lack of adequate electricity and basic needs by a large amount of the population stifle entrepreneurial activity. Getting venture capital to finance entrepreneurial endeavor in Nigeria is very difficult because of the political and economic instability. The policies of the Nigerian government are a barrier to the success of large-scale entrepreneurial success for many Nigerians. The government is plagued by corruption and greed. The government systematically ignores laws that are already in place to promote free enterprise and lack of enforcement of Nigerian patent laws discourages entrepreneurs from commercializing their ideas and inventions. The constant political turmoil in the country greatly limits foreign investors who would be willing to provide resources for entrepreneurship in the country, which is very rich in natural resources. Political and social movements strongly affect the level of entrepreneurial activity in Nigeria. Religious intolerance and ethnic warfare limit country progress in some areas of the country. Female entrepreneurs in Nigeria are often underestimated and overlooked. Female entrepreneurs in Nigeria are often hindered because of cultural barriers such as male/female role definitions that label women inherently inferior to men. Nigeria has the 2nd largest GDP in Africa, South Africa has the largest. The Ibo ethnic group in Nigeria is recognized internationally for its culture of entrepreneurship. Control own life, to be my own boss, freedom to adapt personal approach to work and attain family security are some of the reasons Nigerians engage in entrepreneurial activity.

The Nigerian government has a program in place that promotes exports from Nigeria to other countries, which can be helpful for entrepreneurs looking to do business in Europe or the United States. Lower taxes and 
increased price ceilings have increased the incentives to entrepreneurs in the country. Nigeria is progressively trying to incorporate modern technology into its country. Nigeria is trying to actively promote technology in its educational system with the use of the internet. Although there are a lot of barriers, entrepreneurship in Nigeria is necessary for the country to become a developed nation.

\section{Planning Errors}

According to Koontz and O' Donnell, "Planning is an intellectual process, conscious determination of course of action, the basing of decision on purpose, facts and considered estimates." It is an intellectual process which needs a lot of thinking before a formation of plans. Planning is to set goals and to make certain guidelines achieve the goals. Also, Planning means to formulate policies, segregation of budget, future programs, etc. These are all done to make the activity successful. Planning is an integral part of our life. We make plans in each and every step of life whether it be to go to school or to buy household goods during shopping. We make plans according to the limitations of our budget and resources to get maximum satisfaction and to fulfill goals from our activities

\section{Why engage in the planning process?}

In my mind, there are two primary reasons for engaging in any planning process: celebration and stewardship. Ultimately the "plan" for any spiritual endeavor should reflect what we are trusting God for and not simply how we consume our human energy. When we trust God for something specific and He accomplishes that, we should celebrate His glory. I believe God often does not receive the worship He deserves because we have not prayerfully thought well enough to trust Him for anything specific. The celebration also lifts the eyes of our teams so that they grasp a sense of God's work in their midst. While plans begin by focusing on problems and barriers they should always end with celebration before the Lord.

Stewardship is the other primary reason we must plan. The concept of stewardship has built-in implications. Most certainly it implies that we do not really own the resources that have been entrusted to us; they are on loan from God and therefore must be utilized wisely. Also, our resources are limited and therefore must be invested carefully. Ultimately planning is about the allocation of resources (people, money, time), and if we do that thoughtlessly, then why should God entrust more of His resources to us?

I think there are at least four values making our current strategic planning process (superior to other processes we have used in the past). First, this is a team-based planning process. It works best when we engage our teams in the process, gleaning their wisdom and building their ownership. Second, it is dynamic, not static. In other words it is a plan that should change regularly as God accomplishes what we are trusting Him for. Third, it is vision-focused but thoroughly anchored in reality. (More on this later.) And finally, it aims to be a living, guiding, document that can aid you in providing day-to-day direction for your team. It can and should serve to inform every staff meeting, every student leadership meeting, every planning session, every decision about the focus of your team and the wise use of your precious resources.

Having said all of this it can still be a somewhat cumbersome process to get your arms around and implement effectively. I think this comes primarily from making some common mistakes and giving up on it too quickly. As I have experienced the process, taught the process, and observed it being used, I have seen common errors associated with each of the six steps of strategic planning.

\section{In the Vision: No common direction or passion among the team}

Vision, in my mind, comes from the intersection of four things-passions, dissatisfactions, a strong knowledge of your situation, and calling. Your spiritual passions are those aspects of the ministry that naturally excite you. It maybe laborers for some, changed lives through discipleship or seeing students come to faith. It is easy to have a vision for what gets you naturally excited. Dissatisfactions are those things about the movement, the campus, or students, in general, that bothers you. I am not talking about the annoyances of ministry, but those things that you want to see changed. This may include things like the wounded nature of students today, apathy of Christian students, certain administrative barriers on your campus, or possibly the lack of ethnic diversity represented in your movement. Both of these areas are fertile ground for vision

Anthony, K. A., Igweh, F., \& Stephen, A. (2019). Errors of entrepreneur in Nigeria: the blue ocean strategy as panacea. International Journal of Social Sciences and Humanities, 3(2), 261-276.

https://doi.org/10.29332/ijssh.v3n2.327 
because you already desire change and you can ask God to reveal to you and ponder what that change would look like lived out on your campus.

Constantly being a student of your students, your campus and the collegiate culture, in general, is another place where vision is fueled. Vague or fuzzy knowledge does not inspire, but knowing specific statistics, stories, or people do. Finally, calling is crucial. I define calling as a spiritual sense of "oughtness" tied to an audience. It is that Spirit-empowered heart's desire with college students as the backdrop. Let's review and begin to make some personal application:

1) What are you personally passionate about? How does that connect with the scope?

2) What are you troubled about?

3) What are you learning about your setting? What has God called you to do?

Many teams are simply a collection of personal ministries under the same banner, where there is nothing in which the whole team believes or feels passionate about and therefore nothing for the team to rally around. Vision can be cultivated-it must be. Let's make some team applications:

1) Connect your God-given passions to the mission and to the scope. In other words, if you are already passionate about raising up laborers, could you believe God for more laborers in the current unreached parts of your campus and let that act as a motivation to go there?

2) Regularly have the rest of your team share elements of their passions or dissatisfactions for all to hear-it will rub off on others.

3) Begin to pray through a "vision wish list," asking God to cultivate within each member of the team a growing sense of passion and dissatisfaction about other areas.

4) The goal is not to arrive at a jointly-agreed-upon, "word-smithed" statement; it is to become of one mind and heart towards God's desires for your campus, which happens through a strong sense of spirituality and through a strong sense of mission community.

\section{Situational analysis lacks a brutal assessment of the facts}

Our knowledge is often way too vague to make good, strategic decisions. We rely instead on our "sense" of what students are like and how the movement is doing. Yet the reality is this: students are a moving target. We need to constantly be assessing the key elements of our ministry. Do you know enough to know what you don't know? What must we know?

1) General cultural trends as it relates to college students. There are many great resources for this, including current periodicals, educational journals, web sites, and books.

2) The makeup of your campus: all the hard and soft data that paints the picture of that local setting. This includes statistics about your campus and the movement as well as current attitudes among lost students and students involved with Cru.

3) The makeup of the current movement and past and current ministry effectiveness.

We can only have confidence that we are trusting God to solve the right problems to the degree that we thoroughly know our current situation.

\section{Critical mass: Little intentionality on increasing movement capacity}

It is very easy for leaders to not give attention to this "below-the-line" category, which includes fund development and other spokesperson responsibilities. But it also includes leadership development of staff and student leaders-and we forget that. As leaders you must have double-vision. You must keep one eye on Critical Mass and one eye on the Critical Path.

You can only go up the Critical Path to the degree you have resources to take you there. Here are some observations worthy of reflection:

1) The Critical Path will always scream for your attention.

2) Leadership is primarily about increasing capacity in critical areas: funding, leadership, and tools.

3) You cannot outgrow your capacity.

4) As a leader, you must give a significant amount of your mental, physical, and spiritual energies to Critical Mass. 


\section{Lack of clarity defining problems on path steps}

The Critical Path is about identifying and solving the current, specific, problems you are facing today that are keeping you from making significant progress toward the vision. Most strategic plans I see are largely philosophical plans that simply could be re-labeled win, build, and send. Win, build, and send is our ministry philosophy, but not our strategic plan. And while every critical path step could probably fit into one of our philosophical categories, they should not be nearly that broad in nature. Here are some tests for good Critical Path Steps:

1) Can you envision this problem being solved within a year to a year and a half (The regional level should have path steps that can be solved in 1-3 years; the national level should have path steps that can be solved in 2-5 years).

2) With the solving of this problem, there should be a corresponding increase in Critical Mass and increase in your capacity to fulfill the vision.

3) Are the path steps defined well enough that every member of the team can be guided by them? Can they see how their individual contributions fit into the plan?

\section{An absence of tactical planning in resource release}

Every path step and mass need must be tactically planned to identify roles, goals, tools, and time. Identifying the role means that there is someone or some group who is placed in charge of that particular tactic or strategy. Identifying the goal means that there is a defined and measurable objective established that will help determine the effectiveness of that particular strategy. Identifying the tool or tools means that the necessary means are either created, gathered, or made available to pull off the particular tactic (including funding). And identifying the time component means that there is a time frame for completion (a specific date if it is an event or an ending date if it is a process). The steps again are as follows: roles, goals, tools, and time.

This part of the process (Resource Release) will provide a good check as to the sequence of Critical Path Steps and will highlight Critical Mass resources still needed. It will help you determine how far and how fast you can move up your Critical Path. Don't outpace your capacity. This step is crucial because it keeps strategic plans from being just good thoughts and ideas, and gets them into specific faith strategies that will be executed. This is what makes the plan practical.

\section{Evaluation and learning: seasonal evaluation rather than an ongoing process}

Historically, we have evaluated only in a seasonal manner - at the end of every quarter or semester. We must learn to evaluate in an ongoing way, evaluating each and every tactic as soon as we have determined it has been completed (event or process). The evaluative process does not have to be a long one; many tactics can be evaluated in a few minutes if handled well. This ongoing evaluation will greatly enhance our learning and allow us to respond and make changes more quickly. Plus, the team will be evaluating things while they are fresh, and, therefore. the evaluation will be more specific and helpful. Often, during the seasonal evaluation, we have only vague recollections of what went well or didn't go well back in September, and, as a result, no corrective measures can be taken and the people implementing the plan are not held accountable. Ongoing evaluation will also allow us to better give God glory and depend on Him more specifically. I believe that we can make planning an effective and valuable experience and one that honors the Lord if we will correct some of these errors and seek Him for the guidance we need. Soli Deo Gloria!

\section{Tips for the successful planning}

1) Better a thimble than a Big Gulp. Don't kill your staff by trying to have a two day, sixteen hour planning time. Maybe use several half days over the course of a week to accomplish the same thing.

2) Better a little chaos than sheer boredom. Vary the time, location, and activities of your planning. Aim for a comfortable, relaxed setting that will allow people to move around. If you use part of the time for

Anthony, K. A., Igweh, F., \& Stephen, A. (2019). Errors of entrepreneur in Nigeria: the blue ocean strategy as panacea. International Journal of Social Sciences and Humanities, 3(2), 261-276. 
sheer planning, maybe use some of the other time for information gathering or for group discussion over a current book or periodical that will better inform the team about your mission or your audience.

3) Better to jump start than to keep working a dead battery. When it comes to thinking through specific strategies to accomplish your Critical Path Steps, work by the proposal. Assign two to three staff to come up with some initial ideas that the whole team can interact over and that might later spawn even more ideas. This will save time and keep your team from getting worn out in the process. This might be the afternoon assignment where the group can go off to a Starbucks and be as creative as they can in dreaming up strategies for the next day's discussion.

\section{The Blue Ocean Strategy and Entrepreneurship}

A study on over 150 successful, new market creations across more than 30 industries and less successful competitors revealed that most companies focus on how to beat the competition in open markets. These companies in existence are RED - regularly over-crowed with dwindling profit boundaries and restricted expansion prospects. Furthermore, the profit effect is appreciably higher with creating new market spaces. Besides, market paces, or BLUE OCEANS, can be formed by all types of firms in all types of businesses. Most notably, there seems to be some methodical model that divides thriving, market-creating strategic progress from market-competing strategies (Kim \& Mauborgne, 2005).

Too many business owners are convinced that listening to an advisory board or Board of Directors is a waste of time and money. As a result, they repeat the mistakes of peers and also tend to repeat their own mistakes. Advisors and mentors enhance the learning and effectiveness of even the best business leaders. I'm sure that experienced business owners can add one or two more key items to their assessment list. The reality is that making mistakes is a necessary part of every successful business growth effort, as long as you avoid the mistakes of others, and don't keep making the same mistakes over and over again. The other extreme shortcut is never trying anything new, which is always a mistake in business. You can't win if you don't try to push the limits. Work hard, but work smart.

There is a mistake of trying to launch a new startup before the current one had time to mature. Entrepreneurs lose a lot of resources. However, mistakes need to be made in order to become a better entrepreneur. These mistakes strengthen the experience and culture of a successful entrepreneur. It was a hard time, but it's the mistakes that will help entrepreneurs grow and become successful. Hiring has always been another weakness. On the assumption that I want to believe that because I am a good person, I will always attract good people. I realized that hiring requires a different type of talent, one that is tailored more toward using discernment to discover if a person would be a good fit. Over time, I noticed that it's more about chemistry than skills that work in a people-centered team environment. This is the classic "chicken and egg" problem of which comes first. I assure you that most investors will not take you seriously if you don't have a real company, so you may wait forever.

In the heat of scaling the business, it's tempting to skip the cost and time of finding qualified job candidates and enlist those close at hand, without paying them a competitive wage for the hard work and commitment you need. Very few people are experts in all facets of a new business, including finance, sales, marketing, and operations. The best strategy is to hire people who are smarter than you (in their domain), and allow you to learn from them, rather than the other way around. Moderate business conflict is constructive and should be embraced. New business owners should be signing every payment, and managing every expense. The accountant may accurately record every transaction, but only you can make the strategic trade-offs on marketing costs versus customer revenue, product quality versus support, and so forth.

Kim \& Mauborgne (2003), opined that high performance cannot be sustained by rival in congested businesses (red oceans). Creating blue oceans of uncontested market space is rather the indisputable opportunity. In this paper, we elucidate on the crux of the blue ocean strategy as a panacea to the errors of entrepreneurs in Nigeria.

\section{Creating a win-win Result}

With its integrated approach, blue ocean strategy shows how to align the three strategy propositions value, profit, and people - to ensure your organization is aligned around your new strategy and that it creates 
a win for buyers, the company, and for employees and stakeholders. For any strategy to be successful and sustainable an organization must develop an offering that attracts buyers; it must create a business model that enables the company to make a tidy profit, and it must motivate the people working for or with the company to execute the strategy. While good strategy content hinges upon a compelling value proposition for buyers and a robust profit proposition for the organization, sustainable strategy execution is based largely on a motivating people proposition. The alignment of the three propositions proposed by blue ocean strategy ensures that an organization is taking a holistic approach to the formulation and execution of strategy. Together the three propositions provide an organizing framework for creating a winning strategy that will benefit buyers, the company, as well as internal and external stakeholders.

\section{Creating an Untapped and Uncongested Niche}

Blue ocean strategy doesn't aim to out-perform the competition. It aims to make the competition irrelevant by reconstructing industry boundaries. Whereas conventional strategic approaches drive companies to define their industry similarly and focus on being the best within it, blue ocean strategy prompts them to break out of the accepted boundaries that define how they compete. Instead of looking within these boundaries, managers need to look systematically across them to create blue oceans - new and uncontested market space of new demand and high profitable growth.

\section{Empowerment via BOS Frameworks and Tools}

Blue ocean strategy offers systematic tools and frameworks to break away from the competition and create a blue ocean of uncontested market space. The field of strategy, by contrast, has predominantly focused on how to compete in established markets, creating an arsenal of analytic tools and frameworks to skillfully achieve this.

Blue ocean strategy is built on the common strategic patterns behind the successful creation of blue oceans. These patterns have allowed us to develop underlying analytic frameworks, tools, and methodologies to systematically link innovation to value and reconstruct industry boundaries. The visual and actionable frameworks and tools like the strategy canvas, four actions framework and six paths form the analytic foundations of the blue ocean creation process, bringing structure to what has historically been an unstructured problem in strategy. They provide a roadmap and critical visual guidance for systematically pursuing value innovation and creating uncontested market space. Companies can make proactive changes in industry or market fundamentals through the purposeful application of these blue ocean tools and frameworks.

\section{Gradual Procedural Process}

From assessing the current state of play in industry to exploring the six paths to new market space, to understanding how to convert noncustomers into customers, blue ocean strategy provides a clear four-step process to break away from the competition and create a blue ocean of strong profitable growth. The fourstep process is designed around the concepts and analytic tools of blue ocean strategy and fair process. It is built based on our strategy practices in the field with many companies over the last two decades. It allows managers and their teams to develop rigorous and concrete strategies while capturing the big picture. In this way, it presents an alternative to the existing strategic planning process, which is often criticized as a numbercrunching exercise that keeps companies locked into making incremental improvements.

\section{BOS is grounded in data}

Blue ocean strategy is based on a decade long study of more than 150 strategic moves spanning more than 30 industries over 100 years. Industries ranged from hotels, cinema, retail, airlines, energy, computers, broadcasting, and construction to automobiles and steel. The authors analyzed not only winning business players who created blue oceans but also their less successful competitors. We searched for convergence among the group that created blue oceans and within less successful players caught in the red ocean. They

Anthony, K. A., Igweh, F., \& Stephen, A. (2019). Errors of entrepreneur in Nigeria: the blue ocean strategy as panacea. International Journal of Social Sciences and Humanities, 3(2), 261-276. 
also searched for divergence across these two groups. In so doing, they tried to discover the common factors leading to the creation of blue oceans and the key differences separating those winners from the mere survivors and the losers adrift in the red ocean. As their database and research have continued to expand and grow over the last ten years since the first edition of their book was published, they have continued to observe similar patterns whether blue oceans were created in for-profit industries, non-profit organizations, or the public sector.

\section{Curtails Risk and Exploit Opportunity}

Blue ocean strategy is an opportunity-maximizing risk-minimizing strategy. Of course, any strategy will always involve risks - be it red or blue. However, blue ocean strategy provides a robust mechanism to mitigate risks and increase the odds of success. A key framework here is the Blue Ocean Idea Index. The Blue Ocean Idea Index lets you test the commercial viability of your blue ocean ideas and shows you how to refine your ideas to maximize your upside while minimizing downside risks. It allows you to answer four key questions: First, is there a compelling reason for people to buy your offering? Second, is your offering priced to attract the mass of target buyers so they have a compelling ability to pay for it? Third, can you produce your offering at the strategic price and still earn a healthy profit from it? And finally what are the adoption hurdles in rolling out your idea and have you addressed these upfronts? The first two questions address the revenue side of your business model. They ensure that you create a leap in net buyer value. The third question ensures the profit side of your business model. And the last question ensures that you have given good thought and addressed externalities that could trip up even the best new idea.

\section{Trails low cost and differentiation}

Blue ocean strategy is based on the simultaneous pursuit of low cost and differentiation. It is an "and-and," not an "either-or" strategy. Conventional wisdom holds that companies can either create greater value for customers at a higher cost or create reasonable value at a lower cost. Here the strategy is seen as making a choice between differentiation and low cost. In contrast, blue ocean strategy seeks to break the value-cost tradeoff by eliminating and reducing factors an industry competes on and raising and creating factors the industry has never offered. This is what we call value innovation.

Value innovation is distinctively different from the competitive strategic approach that takes an industry structure as given and seeks to build a defensible position within the existing industry order. The strategic logic of value innovation guides companies to identify what buyers commonly value across the conventional boundaries of competition and reconstruct key factors across market boundaries, thereby achieving both differentiation and low cost and creating a leap in value for both buyers and the company.

\section{Inculcate Implementation into Strategy}

The process and tools of blue ocean strategy are inclusive, easy to understand and communicate, and visual - all of which makes the process non-intimidating and an effective path to building execution into strategy and the collective wisdom of a company.

Equally as important, Blue Ocean strategy is a strategy that expressly joins analytics with the human dimension of organizations. It recognizes and pays respect to the importance of aligning people's minds and hearts with a new strategy so that at the level of the individual, people embrace it of their own accord and willingly go beyond compulsory execution to voluntary cooperation in carrying it out. To achieve this, the blue ocean strategy does not separate strategy formulation from execution. Although this disconnect may be a hallmark of most companies' practices, our research shows it is also a hallmark of slow and questionable implementation and mechanical follow-through at best. Instead, blue ocean strategy builds execution into strategy from the start through the practice of fair process in the making and rolling out of strategy.

Fair Process, namely, engagement, explanation and expectation clarity, prepares the ground for implementation by invoking the most fundamental basis of action: trust, commitment, and the voluntary cooperation of people deep in an organization. Commitment, trust, and voluntary cooperation are not merely 
attitudes or behaviors. They are intangible capital. They allow companies to stand apart in the speed, quality, and consistency of their execution and to implement strategic shifts fast at low cost.

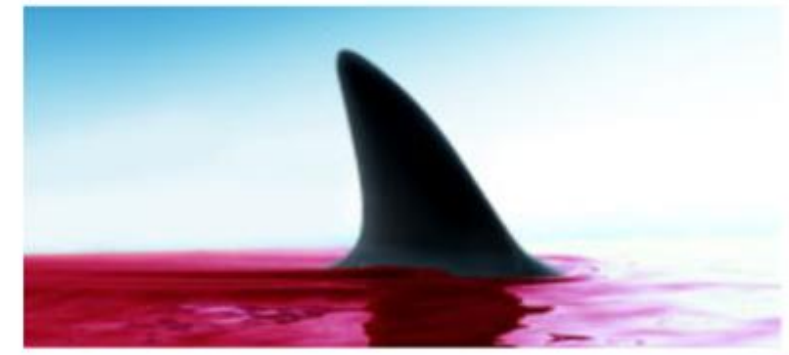

Compete in existing market space

Beat the competition

Exploit existing demand

Make the value-cost trade-off

Align the whole system of a firm's activities with it's strategic choice of differentation er low cost

"Defend Current Position"

Perspective



Create uncontested market space

Make the competition irrelevant

Create and capture new demand

Break the value-cost trade-off

Align the whole system of a firm's activities in pursuit of differentiation and low cost

"Innovate \& Pursue New Opportunities" Perspective

\section{Source: Blue Ocean Strategy Australia}

Figure 1: Diagrammatic dichotomy between the RED and BLUE OCEANS.

\section{Materials and Methods}

The population of the study consists of: the owners, employers, and employees of Small Scale Enterprises. This will include those directly employed by the government and those sourced through the out-sourcing method of recruitment. The population of the study thereby amounts to 60 business organization. A pilot study of 20 organizations executives was conducted using a question on planning error determines success in the face of blue ocean strategy. 18 respondents responded positively by saying "Yes" while 2 disagreed by saying "No". This gave a $0.90(18 / 20)$ probability of success and a $0.10(2 / 20)$ probability of failure.

Thus, with $\mathrm{Z}=1.96$ = Confidence interval

$$
\begin{aligned}
& P=0.90=\text { Probability of success } \\
& G=0.10=\text { Probability of failure } \\
& E=0.05=\text { Standard Error of Estimate }
\end{aligned}
$$

\section{Sample Size and Sampling Techniques}

Due to the difficulties associated with taking the entire population for a study, and in line with the scientific tradition, the sample of the study shall be calculated using the "Tuchman" Formula Sample size Formula as Where $\mathrm{N}=$ Sample size

$\mathrm{Z} \quad=\quad$ Confidence interval

$\mathrm{P} \quad=\quad$ Probability of success

$\mathrm{G}=$ Probability of fairness

$\mathrm{E}=\quad$ Standard error of the estimate.

Anthony, K. A., Igweh, F., \& Stephen, A. (2019). Errors of entrepreneur in Nigeria: the blue ocean strategy as panacea. International Journal of Social Sciences and Humanities, 3(2), 261-276. https://doi.org/10.29332/ijssh.v3n2.327 
and stratified sampling technique was adopted in the selection of the Sample size of the population which becomes

$\mathrm{N}=1.96^{2}(0.90 \times 0.10)$

$(0.05)^{2}$

$=138.30$

$=138$

So, the sample size of the population is 138

Data Analysis Methods

The information gathered from the respondents through the questionnaire formed the basis for data coding and analysis in the study. The descriptive statistics of simple frequency count and simple percentage were used for description and analysis. To test the hypotheses formulated, chi-square method is employed. This method is used because it is good in testing the validity of the hypothetical statement especially to study the relationship between two or more variables.

$\begin{array}{lll}\mathrm{x} 2 & = & (\mathrm{O}-\mathrm{E})^{2} \\ & & \mathrm{E} \\ \text { Where } \mathrm{X}^{2} & = & \text { Is the computed chi-square } \\ \mathrm{O} & = & \text { Is the observed frequencies } \\ \mathrm{E} & = & \text { Is the expected frequencies } \\ \mathrm{S} & = & \text { Is the summation sign; }\end{array}$

While the degree of freedom is $d f=(m-1)(n-1)$. ie. Column $X$ row.

Data Presentation and Analysis

This section presents and analyzes the data gathered in the course of this research. A total of 138 questionnaires were distributed; of which 131 were duly completed and returned.

\section{Results and Discussions}

Testing of Hypothesis

To test for the hypothesis formulated, Chi-square (2) test of independence was used. The decision rule will be to accept the alternative hypothesis $\left(\mathrm{H}_{1}\right)$ if the Chi-square calculated is greater than the chi-square tabulated and reject the null hypothesis accordingly. If the chi-square tabulated is greater than chi-square calculated, the decision rule will be to accept the null hypothesis and reject the alternative hypothesis.

Data Analysis

Table 2

Response Return Rate and Distribution (demographic Data of Respondent)

\begin{tabular}{lllll}
\hline Sex & No Returned & No not Returned & Sub-total & $\%$ Rate \\
\hline Male & 67 & 2 & 69 & $50.0 \%$ \\
Female & 64 & 5 & 69 & $50.0 \%$ \\
Total & 131 & 7 & 138 & $100 \%$ \\
\hline
\end{tabular}




\begin{tabular}{lll}
\hline Age Group & & \\
\hline Under 20 & 17 & $13.0 \%$ \\
$20-29$ & 33 & $25.2 \%$ \\
$30-49$ & 53 & $40.4 \%$ \\
Above 50 & 28 & $21.4 \%$ \\
Total & 131 & $100 \%$ \\
\hline & & \\
\hline Educational Qualification & & $39.0 \%$ \\
\hline FSLC/None & 51 & $41.2 \%$ \\
WASC/SSCE/GCE & 54 & $13.7 \%$ \\
NCE/OND & 18 & $6.1 \%$ \\
NCE/OND & 8 & $39.0 \%$ \\
HND/BSC \& above & 51 & 100 \\
Total & 131 & \\
\hline
\end{tabular}

Source: Fieldwork Analysis, 2018.

The table above shows that 138 questionnaires were distributed to the respondent on equal basis of 69 to male with 67 returned and 2 not returned. 69 to females with 64returned and 5 not returned. The total number of returned questionnaires amount to 131 representing $95.0 \%$ and total not returned were 7 representing $5.0 \%$.

Secondly, the respondent with HND/B.Sc degrees and above were 8 representing 6.1\%; WAEC/GCE/SSCE was 54 representing $41.2 \%$, while respondent with NCE/OND and equivalent were 18 representing 13.7\% and finally, those with FSLC and no certificate at all were 51, representing 39\%.

In addition, the respondent under the age bracket of "Under 20 " were 17, representing $13.0 \%$, those within 20-29 years were 33 representing $25-2 \%, 30-49$ years were 53 representing $40.4 \%$. Finally, those from $50 y$ rs and above were 28 representing $21.4 \%$.

\section{Test of Hypotheses}

The data collected were analyzed. The stated hypotheses were tested with chi-square statistical tool under the following headings.

1) State the hypothesis

2) State the statistical tools used

3) Test the hypothesis

4) State the decision rule

5) Take the decision

Test of Null Hypothesis ( $\left.\mathrm{Ho}_{1}\right)$

1) Statement of Hypothesis

Ho: The Planning Errors do not reduce Entrepreneurs success in Nigeria

2) The statistical tools used.

Chi-square was used in this study is as follows:

$$
X^{2}=\left(O-E^{2}\right)
$$

Where $\quad \mathrm{X}^{2}=$ is the computed chi-square

$0=$ is the observed frequencies

$\mathrm{E} \quad=\quad$ is the expected frequencies

$\mathrm{S}=$ Is the summation sign

The above table was used for this analysis.

Anthony, K. A., Igweh, F., \& Stephen, A. (2019). Errors of entrepreneur in Nigeria: the blue ocean strategy as panacea. International Journal of Social Sciences and Humanities, 3(2), 261-276. 
3) Testing the hypothesis

Table 3

Calculation of chi-square for hypothesis one $\mathrm{H}_{0}$

\begin{tabular}{llllll}
\hline Responses & $\mathrm{O}$ & $\mathrm{E}$ & $\mathrm{O}-\mathrm{E}$ & $\mathrm{O}-\mathrm{E}^{2}$ & $0-\mathrm{E}^{2} / \mathrm{E}$ \\
\hline Yes & 111 & 84.7 & 26.3 & 691.7 & 8.17 \\
No & 20 & 15.3 & 4.7 & 22.09 & 1.45 \\
Total & 131 & 100 & & & 9.62 \\
\hline
\end{tabular}

Computed chi-square (X2) $=9 \mathrm{~m} .62$.

Table value

$=3.84(\mathrm{X} 20)$

Df

$=(\mathrm{m}-1)(\mathrm{n}-1)$

df

$=(2-1)(2-1)=\mathrm{df}=1 \times 1=1=3.84$.

4) State the decision rule

A decision rule is the statistical objective procedure, which guides the researcher as to whether a particular hypothesis is accepted or rejected from a set of data.

In testing the above hypothesis, the decision rule state that at 0.5 level of significance with 1 degree of freedom, of the calculated value of chi-square $\mathrm{X}^{2}>\mathrm{X}^{2} 0$ reject Ho and accept $\mathrm{H}_{1}$, where $\mathrm{X}^{2} 0$ is the table value of 3.84 .

5) Take the decision

The chi-square shows that the calculated value of 9.62 is greater than the table value of 3.84 at 1-degree freedom and at a probability level of 0.5 . So the $\left(\mathrm{H}_{0}\right)$ null hypothesis is rejected and the alternative hypothesis $\mathrm{H}_{1}$ upholds, that planning errors reduces entrepreneur's success in Nigeria.

\section{Test of Null Hypothesis ( $\left.\mathrm{H}_{02}\right)$}

1) Statement of Hypothesis

$\mathrm{H}_{2}$ : Blue Ocean strategy do not promote the success of Entrepreneurs in Nigeria

2) The statistical tools used

Chi-square was used as the statistical tool to test the hypothesis. The formula for chi-square for this study is as follows.

$\begin{array}{lll}\mathrm{X}^{2} & = & \text { computed chi-square } \\ \mathrm{O} & = & \text { Observed frequencies } \\ \mathrm{E} & = & \text { Expected frequencies } \\ \mathrm{S} & = & \text { Summation sign }\end{array}$

3) Testing the hypothesis

Table 4

Calculation of chi-square for hypothesis two $\left(\mathrm{H}_{02}\right)$

\begin{tabular}{llllll}
\hline Responses & $\mathrm{O}$ & $\mathrm{E}$ & $\mathrm{O}-\mathrm{E}$ & $\mathrm{O}^{-} \mathrm{E}^{2}$ & $\mathrm{O}^{2} \mathrm{E}$ \\
\hline Agreed & 89 & 68 & 21 & 441 & 6.49 \\
Disagreed & 40 & 31 & 9 & 81 & 2.6 \\
Undecided & 2 & 1 & 1 & 1 & 1 \\
Total & 131 & 100 & & & 10.09 \\
\hline
\end{tabular}

Source: Fieldwork analysis

Computed chi-square $\left(\mathrm{X}^{2}\right)=10.09$

Table value $=\left(\mathrm{X}^{2} 0\right) 5.991$ 
4) State the decision rule

The decision rule states that 0.5 level of significance, with 2 degrees of freedom, if the computed chi-square value $\mathrm{X}^{2}>\mathrm{X}^{2} 0$, reject null hypothesis (H02) and accept alternate hypothesis $\left(\mathrm{H}_{2}\right)$, where $\mathrm{X}^{2} 0$ is the table value of 5.99 .

5) Take a decision

The chi-square shows that the calculated value of10.09 is greater than the table value of 5.99 at 2 degrees of freedom and at a probability level of 0.5. This result shows that the alternate hypothesis (H2) that represents the positive response tested significant and it was accepted that Blue Ocean strategy promotes success of Entrepreneurs in Nigeria especially in boosting small scale enterprises as feeders of larger industries

\section{Conclusion}

This study is an attempt at analyzing how the application of the Blue Ocean Strategy will help in enhancing the planning and service delivery of entrepreneurs in small scale enterprises. The misplacement of official interest for personal benefit that has characterized the Nigeria bureaucratic settings has in no small way curtailed the extent to which national development is achieved. It was discovered through this study that government spending on critical infrastructure is very low and that is why entrepreneurs tend to concentrate on bigger cities more with less emphasis on growing other parts of the society. Also, the knowledge gap in taking calculated risk has not helped the system at all as entrepreneurs are not ready to venture into the unknown. There is no gainsaying therefore that the success or otherwise of any organization depends on how effective their plans are

\section{Recommendations}

1) It was recommended that those entrepreneurs who stuck in the red oceans should employ the Blue Ocean Strategy's analytical tools and frameworks. Someone definitely created every business and market space while it was new.

2) The approach to the growth and incubation of entrepreneurship should be seen as a critical issue in Nigeria

3) Entrepreneurs should seek consultancy approach to avoid planning errors and adopt good planning structure

\section{Acknowledgments}

The authors would like to thank the editor of IJSSH for their valuable time, support, and advice in completing the current study.

\footnotetext{
Anthony, K. A., Igweh, F., \& Stephen, A. (2019). Errors of entrepreneur in Nigeria: the blue ocean strategy as panacea. International Journal of Social Sciences and Humanities, 3(2), 261-276. https://doi.org/10.29332/ijssh.v3n2.327
} 


\section{References}

Ajadi, I. A. (2010). Blue Ocean Strategy: A Panacea to the Menace of Bureaucratic Corruption in Nigeria.

Bolarinwa, J. O. (2005). Bureaucratic corruption in Africa: the futility of cleanups. The Nigerian Journal of Economic History, (7-8), 164-185.

Kim, C., Yang, K. H., \& Kim, J. (2008). A strategy for third-party logistics systems: A case analysis using the blue ocean strategy. Omega, 36(4), 522-534. https://doi.org/10.1016/j.omega.2006.11.011

Kim, W. C. (2005). Blue ocean strategy: from theory to practice. California management review, 47(3), $105-121$. https://doi.org/10.1177\%2F000812560504700301

Kim, W. C., \& Mauborgne, R. (2005). Blue Ocean Strategy: How to Create Uncontested Market Space Competiton Irrelevant.

Mauborgne, L. (2004). Astrée: Verification of absence of runtime error. In Building the Information Society (pp. 385-392). Springer, Boston, MA. https://doi.org/10.1007/978-1-4020-8157-6_30

Ogundiya, I. S. (2011). Anti-corruption reforms in Nigeria: challenges and failures. Assessment of Democratic Trends In Nigeria, 191-209.

Oosterbroek, J. W. (2007). Curtailing corruption in the European Univon: an Asian approach to combat corruption in the European Union (Bachelor's thesis, University of Twente).

\section{Biography of Authors}

\begin{tabular}{|c|c|}
\hline & $\begin{array}{l}\text { Dr. Kifordu Anyibuofu Anthony holds a BSc, Business Administration and } \\
\text { Management, MSc, Ph.D., PGDE, and MEd degrees. He has taught in Delta State } \\
\text { University, Abraka, and College of Education Agbor. He was the Pioneer Ag. Head, } \\
\text { Department of Accounting, Business Administration and Economics, Edo } \\
\text { University Iyamho, Edo State. Currently, he doubles as the Ag. Head, Business } \\
\text { Administration / Entrepreneurship Department, and Director Entrepreneurship } \\
\text { Development Centre and Linkages, Edo University Iyamho, Edo State. } \\
\text { Email: anthony.kifordu@yahoo.com }\end{array}$ \\
\hline & $\begin{array}{l}\text { Dr, Florence was born on 26th August } 1975 \text { and holds a BSc in Sociology, Post } \\
\text { Graduate Diploma in Management, MBA, MSc Management and Ph.D. } \\
\text { Management. She has publications in the fields of human resources and general } \\
\text { management. She has brought her wealth of experience in the area of HRM and } \\
\text { presently the Head, Department of Human Resources Management Delta State } \\
\text { Polytechnic Ogwashi-Uku, Delta State. She is happily married with children and } \\
\text { relaxes with reading and football. } \\
\text { Email: tatiigweh@gmail.com }\end{array}$ \\
\hline & $\begin{array}{l}\text { Dr, Stephen holds a BSc, Business Administration, MSc Management and Ph.D. } \\
\text { Management. His expertise is in quantitative applications and has published } \\
\text { articles in humanities. He is a member of various professional bodies and } \\
\text { currently a Lecturer in the Department of Human Resources Management, Delta } \\
\text { State Polytechnic Ogwashi-Uku, Delta State. He is happily married with children } \\
\text { and loves football. } \\
\text { Email:agborstephen@gmail.com }\end{array}$ \\
\hline
\end{tabular}

